\title{
UNA ALTERNATIVA FISIÓCRATA AL INFORME DE LEY AGRARIA DE JOVELLANOS *
}

\author{
JESÚS ASTIGARRAGA \\ Universidad de Zaragoza $^{\mathrm{a}}$ \\ JAVIER USOZ \\ Universidad de Zaragoza ${ }^{\mathrm{a}}$
}

A Lluís Argemí d'Abadal, In Memoriam

\begin{abstract}
RESUMEN
Este trabajo se enmarca en el estudio de la recepción que conoció en España el Informe de Ley Agraria (1795) de Jovellanos. En particular, se centra en una traducción inducida por esta obra, la realizada por J. Álvarez Guerra de un importante texto agronómico del francés F. Rozier. Aunque esta traducción ya ha sido destacada como un logro fundamental de la agronomía ilustrada española, hasta la fecha no se ha prestado ninguna atención al "Discurso Preliminar» que la introducía. Este "Discurso» contenía un resumen muy completo de las ideas económicas fisiócratas. Esto permite su caracterización como una alternativa fisiócrata al Informe de Jovellanos, lo cual, a su vez, posee implicaciones interpretativas respecto, principalmente, a dos cuestiones: una reconsideración más positiva de la presencia de la fisiocracia en nuestras Luces y la aceptación de que la opción librecambista fue una parte consustancial, si bien minoritaria, al programa económico de la Ilustración española.
\end{abstract}

* Receibed 04/18/2007. Accepted 11/08/2007. Este artículo se adscribe al Proyecto de Investigación HUM-00537 del Ministerio de Educación y Ciencia.

a Departamento de Estructura e Historia Económica y Economía Pública, Facultad de Derecho, c/ Pedro Cerbuna, 12, 50009 Zaragoza. astigarr@unizar.es, jusoz@unizar.es. Los autores desean agradecer expresamente las valiosas críticas y sugerencias recibidas de los evaluadores de esta publicación. 
Palabras clave: Circulación internacional de las ideas económicas, Ilustración económica española, Fisiocracia, Agronomía, Jovellanos, Juan Álvarez Guerra

\begin{abstract}
The frame of this work is the reception that Jovellanos' Informe de Ley Agraria (1795) known in Spain. It is specially focused on the Spanish translation of a conspicuous agronomic work by F. Rozier, a French author. The translation was induced by the Informe and was elaborated by J. Álvarez Guerra. It has been considered as a notorious achievement of the Spanish agronomic movement of the Enlightenment. Nevertheless, the translator's «Discurso Preliminar» has not already been studied. This «Discurso" included an entire summary of the economic ideas of the French Physiocracy, so it allows us to consider it as a Physiocrat alternative of the Jovellano's Informe. Two different issues are particularly involved by this research: firstly, the influence of Physiocracy in Spain was stronger than it has been recognised; secondly, free trade was consubstantial to the Spanish economic program of the Enlightenment, although always as a minority option.
\end{abstract}

Keywords: International circulation of the economic ideas, Spanish Economic Enlightenment, Physiocracy, Agronomics, Jovellanos, Juan Álvarez Guerra

JEL Classification: B11, B31, N53

\title{
1. INTRODUCCIÓN
}

A día de hoy resulta indiscutible que la política de comercio y aprovisionamiento de granos constituyó un elemento central de los debates que acompañaron el tránsito de las economías europeas desde el Antiguo Régimen al sistema liberal y que esos debates encerraron una diversidad de factores de enorme trascendencia de cara a la interpretación de aquellos elementos que favorecieron ese tránsito, toda vez que en ellos se hallaban implicadas cuestiones no sólo económicas, como la garantía de la subsistencia de la población o el crecimiento del Estado, sino también otras de índole política o, sencillamente, de estricto orden y control sociales ${ }^{1}$. La política de granos - $\mathrm{O}$, más en general, la de natu-

\footnotetext{
1 Para un magnífico análisis sobre esa cuestión, vid. Kaplan (1976, pp. 1-51).
} 
raleza agrícola - fue también una preocupación central de la Ilustración española, en particular, durante el período, notable, en los ámbitos de la circulación de las ideas y de las reformas económicas y políticas, que se abrió en ella durante el reinado de Carlos III. De acuerdo con Artola (1978, pp. 128, 136), se dio inicio entonces a un conjunto de transformaciones agrícolas que, aunque no exento de vacilaciones y contradicciones, trató de reorientar la secular política de abastos baratos favorables al consumidor hacia un programa de desarrollo económico destinado a promover el crecimiento de la producción. Y si, a medida que vamos conociendo más en profundidad el contenido de esas transformaciones, va aflorando la percepción de que la Ilustración española disfrutó de una cierta pluralidad interna, en términos territoriales, cronológicos y doctrinales, resulta indiscutible la importancia que en ella desempeñó el Expediente de Ley Agraria como un gran espacio polarizador de los debates agrícolas durante el período transcurrido desde abril de 1765, cuando fue iniciado por la Secretaría de la Real Hacienda con el fin de averiguar los «medios más convenientes para fomentar la labranza y la ganadería», hasta finales de 1795, cuando la Sociedad Matritense, casi dos décadas después de haberse responsabilizado del mismo, publicaba en su colección de Memorias el Informe de Ley Agraria de Jovellanos $^{2}$.

Por su parte, también está fuera de discusión la trascendencia del Informe como uno de los manifiestos económicos fundamentales de la Ilustración española. Su detallado estudio de los «estorbos» para el desarrollo agrícola de naturaleza «política», «moral» $\mathrm{y}$ «física», provenientes respectivamente de la «legislación», la «opinión» o la «naturaleza», y las correspondientes medidas de «libertad», «luces» y «auxilios» como fundamentos de la actuación pública con el fin de remover cada uno de esos «estorbos», ha sido valorado como una culminación de los análisis de nuestros ilustrados en relación al funcionamiento del sistema agrícola y, al mismo tiempo, como una medida de las auténticas posibilidades de maniobra que poseía el reformismo español de finales del siglo XVIII. En cualquier caso, la generación de reformadores coetáneos de Jovellanos, que, bajo el liderazgo de autores como Foronda o Cabarrús, afloraron en la etapa de la Ilustración tardía durante la cual fue elaborado el Informe, es menos conocida que la que la antecedió. En las páginas que siguen se atiende a un miembro de la misma todavía poco estudiado, Juan Álvarez Guerra, y, en particular, a la traducción que emprendió, poco después de publicado el Informe, del texto agronómico principal del francés F. Rozier. Aunque esta traducción haya sido destacada de manera reiterada como una pieza notable en la historia de la agronomía

${ }^{2}$ Sobre la historia de la Ley Agraria en España, vid. Anes (1995, pp. 137-163; 1996a). 
ilustrada española, la atención de este trabajo se dirigirá a una importante memoria de contenido fisiócrata que fue incorporada por el traductor a la misma, bajo la forma de un «Discurso Preliminar», y que, a pesar de ser realmente singular en el contexto de la Ilustración española, ha pasado desapercibida hasta la fecha ${ }^{3}$.

\section{LA TRADUCCIÓN ESPAÑOLA DEL COURS DE ROZIER: SUS RAZONES}

En 1797 vio la luz el primer volumen de los dieciséis que, después de seis años, en 1803, compondrán la traducción española íntegra del Cours complet d'agriculture (1781-1800) del Abbé François Rozier (1734-1793). Obra de formato alfabético, publicada en diez volúmenes entre 1781 y 1800, parcialmente póstuma y colectiva en cuanto a su autoría ${ }^{4}$, el Cours representó, sin duda alguna, la realización más acabada de este prolífico e influyente naturalista, botánico y agrónomo francés. Rozier, cuya proyección intelectual debió mucho al apoyo político que le prestó Turgot, fue un insigne sucesor de H. Duhamel de Monceau, H. Patullo o M. Dupuy-Demportes, cabezas visibles de la primera generación de agrónomos franceses que había comenzado a difundir en su país los principios, eminentemente técnicos y relativos a la organización de los cultivos, de la denominada agricultura nueva, dos décadas después de que a comienzos de los años treinta J. Tull hubiera asentado en tierras británicas sus fundamentos originales. Precisamente, según Bourde (1967, vol. III, pp. 1590, 1062-1063), el Cours de Rozier constituyó una especie de «summa de la agricultura nueva», al sistematizar los «resultados de treinta años de experiencias e investigaciones». Las voces que integraban este voluminoso diccionario o enciclopedia rural -algunas de ellas eran tratados temáticos completos, con sus correspondientes secciones y artículos-fueron concebidas como manual de uso para la mejora por el agricultor de la explotación de sus tierras y poseían un indiscutible afán sistemático. Ello terminó por transformar la obra en una auténtica

3 De la adscripción fisiócrata de esa memoria se ofrecía una primera interpretación en Astigarraga-Zabalza (2006).

${ }_{4}$ Mientras los nueve primeros volúmenes se atribuyen al propio Rozier, en la elaboración del décimo y póstumo participaron autores de la talla de Chaptal, Cadet-de-Vaux o Parmentier. La obra sería completada en 1805 con dos volúmenes adicionales, que la traducción española, finalizada en 1803, no incorporó. Ésta tampoco incluyó finalmente un "suplemento», previsto por el traductor, que sirviera para introducir rectificaciones en las voces publicadas y para publicar un diccionario francés-castellano de voces agronómicas, dado que numerosos vocablos del único Diccionario lexicográfico español con una cierta atención a las artes y oficios, obra de E. Terreros (1786-1793), estaban «equivocados o confundidos». Vid. Rozier [1797-1803, vol. XVI (1803), pp. 471-474]. 
enciclopedia de las ciencias agrícolas, que comprendía conceptos botánicos, médicos, veterinarios o de historia natural, sin género de duda, una de las mejores de todo el siglo XVIII europeo, de carácter no sólo técnico o científico, sino también abierta a los problemas filosóficos y sociales de la economía rural. Rozier, miembro, entre otras diversas instituciones de su tiempo, de la prestigiosa Academia de Ciencias de París, ponía sus ideas agronómicas al servicio de una sociedad rural armónica $\mathrm{y}$, en este sentido, su obra ha sido apreciada como una precursora de autores como Fourier. En cualquier caso, en cuanto obra enciclopédica cumbre de la agricultura nueva, su Cours fue una poderosa vía para la difusión internacional de los principios de esta característica corriente agronómica de la Ilustración anglo-francesa durante los años de tránsito de los siglos XVIII al XIX.

Por su parte, respecto a la llegada de esa obra a España, originariamente debe interpretarse en el marco de dos líneas centrales de nuestra Ilustración: en primer lugar, el interés que venía despertando en ella la agricultura nueva, al menos desde 1751, cuando Campomanes promovió la traducción española del influyente Traité (1750) de Duhamel de Monceau, y con una intensidad mucho mayor a partir de 1765, momento en que la agromanía característica de los círculos ilustrados europeos comenzó a hacerse notablemente visible también en nuestro país ${ }^{5}$; y, en segundo lugar, la demanda, políticamente muy expresiva en los Discursos de 1774 y 1775 de Campomanes y muy reiterada en el último cuarto del siglo XVIII, acerca de la falta de diccionarios españoles de artes y ciencias aplicadas, la agricultura incluida. Como otras tantas expresiones del movimiento ilustrado español, ambas cuestiones encontraron un claro reflejo en el Informe de Jovellanos, de ahí que la traducción española de Rozier, emprendida pocos meses después de que éste fuera publicado, deba ser interpretada en el contexto preciso del debate político e intelectual que indujo esta obra cumbre de la Ilustración española.

En su análisis sobre la manera de superar los estorbos «morales o derivados de la opinión» —es decir, los producidos por las opiniones contrarias a la idea de que la agricultura era la «primera de todas las artes» y que, por tanto, agudizaban el atraso en el arte del cultivo, perpetuando la imperfección de los métodos y los instrumentos de labor-, Jovellanos (1795, pp. 304-318) había insistido en la importancia del fomento de la instrucción publica, tanto de la general, como de la que, difundiendo los principios teóricos y prácticos de la agricultura, tuviera una influencia más inmediata en la perfección de los métodos de cultivo. Ello exigía prestar atención a la instrucción de los propietarios y los labradores a través

5 La mejor guía sigue siendo Argemí (1985; 1989). También puede verse García Sanz (1974) 
de seminarios, cátedras o la enseñanza de primeras letras, así como de obras de diseminación de los conocimientos agrícolas, como las cartillas rústicas. En esta labor técnica y educativa de sentido popularizador, que siempre había preocupado al asturiano ${ }^{6}$, debían implicarse las Sociedades Económicas, a las que atribuía como primera dedicación la agricultura, o los párrocos rurales, reafirmando una reivindicación muy presente en el siglo XVIII español (Campomanes, Díaz Valdés, etc.). Lógicamente, la trascendencia de estas cuestiones parecía especialmente acuciante a finales de ese siglo, cuando, culminado el ciclo del crecimiento agrícola a través de la extensión de los cultivos, la salida más evidente para la agricultura española era generalizar, ya sin más dilación, esas mejoras de carácter técnico e intensivo que venían siendo reclamadas desde la década de los sesenta por amplios sectores de la Ilustración española.

La traducción de Rozier venía a cubrir perfectamente esa labor de información e instrucción reclamada por Jovellanos, si bien a través de una vía - las obras de formato alfabético- no mencionada expresamente en su Informe. De hecho, la elaboración de esa traducción se inscribe en el momento de mayor intensidad de todo el siglo XVIII español en la pretensión de realizar una obra enciclopédica sobre temas agrícolas, una cuestión que ha pasado desapercibida en los estudios acerca de la recepción que encontró la obra de Jovellanos. Actualmente, se dispone de informaciones suficientemente expresivas de dicha recepción, que vienen a contradecir la tesis clásica de que el Informe apenas tuvo efectos doctrinales y prácticos con anterioridad a que las Cortes de Cádiz declararan a su autor «benemérito de la patria» y comenzaran una decidida supresión de la legislación feudal heredada del Antiguo Régimen ${ }^{7}$. Una vez que en 1794, en un clima no siempre favorable a la «cruzada liberal» de Jovellanos, la Sociedad Matritense aprobara y elevara el texto al Consejo, y que éste, con Godoy siempre presente, admitiera su publicación un año después en las Memorias de la propia Sociedad, la obra se vio envuelta en el lógico debate que su altura exigía. Despertó elogios, si bien matizados, entre ilustrados próximos a Jovellanos (Meléndez Valdés, Fernández Navarrete, Pereyra...), objeciones críticas (Floranes, en particular, respecto a sus ideas desamortizadoras) e indujo la redacción por parte de Cabarrús de sus conocidas Cartas, en las que planteaba un programa económico y político notablemente más audaz que el expuesto en el Informe. Al mismo tiempo, a éste se le atribuye una cier-

${ }^{6}$ Acerca de su ilustrativa propuesta a la Matritense en 1786 para la creación de una gaceta económica, vid. Domergue (1969, pp. 55-58).

7 Sobre la difícil coyuntura agrícola que acogió el Informe, puede verse Castro (1987, pp. 175-180), sobre su repercusión práctica en el ámbito legislativo, Anes (1995, pp. 173183), y sobre su acogida en los ambientes políticos e intelectuales de finales de siglo, Domergue (1971, pp. 71-74), Varela (1988, pp. 128-146) y Llombart (2000, pp. 119-130). 
ta influencia como fundamento doctrinal de diversa legislación desamortizadora, hacendística y de otra índole decretada a partir de 1797. Es indudable, no obstante, que esta aplicación inmediata de las ideas de Jovellanos fue más reducida de lo que él mismo confiaba, en parte debido a la difícil coyuntura agrícola y a la notable crisis del sistema de pósitos que España venía padeciendo a partir de 1788-1789; también al expediente que en enero de 1796 incoó la Inquisición al Informe, y que el Consejo — quizás, el propio Godoy- hubo de suspender en julio de 1797; así como, por último, al gradual enrarecimiento del clima intelectual y político durante la etapa de Godoy, cuestiones que provocaron que la elaboración de una Ley Agraria dejara de ser una prioridad para la política gubernamental. Pero, ahondando en esa misma tesis que sostiene una recepción activa rápida del Informe, se debe llamar la atención sobre su incidencia, también inmediata, en el ámbito de la popularización de los conocimientos de la economía rural ${ }^{8}$. Precisamente, ése era el terreno concreto que acogió en 1797 al pionero Seminario de Agricultura y Artes ${ }^{9}$ y en el que se emplazó, a partir de ese mismo año, la traducción del Cours de Rozier.

\section{LA TRADUCCIÓN ESPAÑOLA DEL COURS DE ROZIER: SU AUTOR Y SU CONTEXTO INSTITUCIONAL}

Respecto al traductor español del Cours, Juan Álvarez Guerra era un joven sin ninguna proyección pública ni experiencia política cuando emprendió su traducción, de tal manera que ésta constituyó su primera contribución visible a la causa ilustrada. A pesar de ello, estaba destinado a desempeñar un papel de primera línea, junto a dos de sus hermanos menores, Andrés y José, como publicista, editor, escritor y político en el seno de las corrientes liberales españolas durante las cuatro primeras décadas del siglo XIX ${ }^{10}$. Nacido en Zafra y miembro de una dis-

8 Como se explica con detalle en Astigarraga-Zabalza (2006), en los últimos años del siglo XvIII C. Nova Palacio trató de traducir el Dictionnaire del agrónomo francés J. C. Valmont de Bomare, J. de Villalba de elaborar un «diccionario de higiene y economía rural y veterinaria»y, por último, A. Merino de realizar una ambiciosa «Enciclopedia de Agricultura», proyectos que no fueron culminados. Vid. AHN, Estado, leg. 2932-23 y 3182-151, y Villalba (s.a.).

9 Según Díez (1980, pp. 33 y ss.) esta publicación periódica promovida por Godoy, que se mantuvo activa entre 1797 y 1808, fue un claro producto derivado del Informe de Jovellanos.

10 En Pérez (1995) y Gil (1991, pp. 29-30) puede encontrarse una breve biografía de J. Álvarez Guerra. También es útil a ese respecto su expediente como Prócer del Reino depositado en el AHS (His-0024-06). Su interés por las cuestiones agronómicas y la apicultura ha sido objeto de estudio por Jaime-Jaime (2003). En Dérozier (1978, pp. 265-267, 374-375 
tinguida familia terrateniente de esta localidad extremeña, Juan (Zafra, 1770-Madrid, 1845) cumplió, de manera casi canónica, con el formato habitual de las trayectorias vitales de los principales miembros liberales de su generación. Una vez finalizada su carrera de Leyes en la Universidad de Salamanca, en 1795 se instaló en Madrid, para trabajar como abogado. Allí inició su inserción en la estructura institucional ilustrada; su primer ámbito fue la Sociedad Matritense, en la que ingresó en 1794. Pocos años después lo haría su trayectoria política. Asesor en 1807 de la Junta de Comercio y combatiente a partir de 1808 en Extremadura frente al invasor francés, durante 1812-1840 Álvarez Guerra trabajará en la primera línea de la política española, al lado de M. Quintana, A. Argüelles, J. J. García, D. Muñoz Torrero y tantos otros miembros del núcleo liberal salmantino, tan influyente en la concreción y la materialización del programa liberal español pergeñado por las Cortes de Cádiz. De su indudable ascenso político durante esa primera etapa constitucional da fe su nombramiento en marzo de 1813 como Ministro de la Gobernación. Ahora bien, como la mayoría de sus correligionarios, Álvarez Guerra conoció también en primera persona la represión que acompañó al giro absolutista de 1814: al mismo tiempo que sus bienes eran embargados, fue apresado —en el penal de Ceutay deportado - a Mallorca-, junto a A. Argüelles. La nueva llegada de los liberales al poder dio inicio a su etapa política más intensa, tan sólo interrumpida tras 1824, cuando se vio obligado a retirarse discretamente en su localidad natal. Entre otros diversos servicios a la causa liberal, fue Diputado en las Cortes del Trienio liberal, junto a D. Muñoz Torrero o J. J. García, en representación de Extremadura, Prócer del Reino —en 1834-, Ministro del Interior —en 1835- y, por último, Director General de Correos — de 1837 a 1840-. Su carrera política, normalmente entre los «más templados de las filas liberales» y, llegado el momento, en el Partido Liberal Moderado, se vio acompañada de sus actividades empresariales en la Baja Extremadura, así como de su participación en algunas de las instituciones culturales más emblemáticas

y 660-673) se explican sus relaciones políticas y periodísticas, antes, durante y después de las Cortes de Cádiz, con el liberal M. Quintana, con quien fundó la revista Variedades de ciencias, literatura y artes (1804) y colaboró en el Semanario patriótico (1808). También fue redactor jefe del Diario de Badajoz (1808), órgano de la Junta Suprema de Extremadura, y, según Recio (1958, p. 110), colaborador del Correo Mercantil de España y sus Indias. Años después mantuvo intensas relaciones con el editor extremeño exiliado en Londres, M. Calero, con quien colaboró en el Semanario de Agricultura y Artes (1829). Por último, interesantes datos de la biografía de este notable miembro de la masonería figuran en sendas Tesis doctorales realizadas por García de la Barrena (1992, pp. 125 y ss., 241-243) y Pérez (2000, pp. 7-145) sobre su hermano Andrés, cuyos trabajos filosóficos, a menudo atribuidos erróneamente al propio Juan, están considerados precursores de Sanz del Río y los krausistas — García de la Barrena (1992, pp. 349 y ss.)—. 
de su tiempo, como la Academia Nacional —en la sección de Ciencias Físico-Matemáticas_ o la Sociedad Matritense, de la que fue Director entre 1835 y 1842. Su formación universitaria jurídica no impidió su vertebral dedicación intelectual, como escritor y articulista en numerosas publicaciones periódicas del primer tercio del siglo XIX, a cuestiones de ciencias aplicadas que, en la vertiente más cercana a la Economía, lo convirtió en un autor especialmente interesado por las cuestiones agrarias, una faceta que sus biógrafos identifican como una herencia intelectual de su padre Francisco Javier, además de hacendado innovador, articulista sobre estos temas, y que, como otras dimensiones de su obra, no es todavía bien conocida. El primer reflejo de ese interés de Juan por la economía rural fue precisamente su traducción del Cours de Rozier, que emprendió poco después de asentarse en Madrid, cuando no había cumplido aún la treintena de años.

Sobre los detalles materiales de esta traducción, es indudable que su marco institucional fue la Sociedad Matritense, durante los años inmediatamente posteriores a que ésta publicara el Informe de Jovellanos. No obstante, Rozier era un autor bien conocido en el interior de la Sociedad antes de ser traducido. En 1778, cuando el francés ya era considerado un autor de prestigio europeo en cuestiones de botánica, física e historia natural, había remitido por su propia iniciativa un pormenorizado proyecto para la creación en España de una escuela de agricultura. Su diseño era realmente ambicioso, algo que refuerza la idea de Bourde (1967, vol. III, pp. 1591-2) de que precisamente en esos años la agronomía estaba comenzado a ser considerada en Francia una disciplina académica respetable. Rozier pretendía que la escuela fuera una institución de carácter nacional, en la que se ejercieran «todos los métodos de cultivo conocidos en España» y se compararan «unos con otros por los alumnos, que han de concurrir de todas las provincias del Reino», razón por la cual proponía que se localizara en el centro de la Península. Al mismo tiempo, estaba destinada a la difusión de las prácticas del buen cultivo, por medio de lecciones, cartillas rústicas para los párrocos, etc., a partir de la cual el agrónomo francés confiaba en que se produciría una «ventajosa mudanza general» de la agricultura en las provincias españolas. Precisamente, debido a su carácter nacional, este proyecto, que el propio Rozier se ofrecía a dirigir, se presentó a la Matritense como el «Bosquejo de un plan de agricultura para España». Ahora bien, una vez traducido y después de sendos informes críticos con su contenido, realizados por miembros de la Clase de Agricultura de la Sociedad, fue rechazado por ésta ${ }^{11}$. En cualquier caso, su tratamiento de este

11 Sus autores, F. Fernández Molinillo y A. Aguilera, consideraban que el proyecto era un "pensamiento imaginario», de «casi impracticable ejecución», que difícilmente podía ser 
expediente fue muy cuidadoso, todo un indicio de que para esa fecha Rozier era un autor prestigioso también entre los ilustrados españoles. Por este motivo, nada extraña que, como explica Pérez (1995, p. 43), pocos meses después, ante la llegada a España de los primeros ecos de la publicación inminente en Francia del Cours de Rozier, y antes incluso de que comenzara su distribución de la mano del poderoso librero francés asentado en Madrid S. Thevin, el socio F. Fernández Molinillo propusiera emprender su traducción colectiva, "por ser para uno sólo empresa bastante trabajosa».

En alguna medida, éste fue el proyecto que retomará años después Álvarez Guerra. Una vez ingresado en la Matritense en noviembre de 1794, su Clase de Agricultura, en la que quedó integrado, le solicitó ayuda para valorar diversas memorias remitidas a un concurso sobre fomento de la apicultura ${ }^{12}$. El uso intensivo que para resolver esta solicitud hubo de hacer del Cours de Rozier le incitó a proceder de inmediato a su traducción. De acuerdo con sus afirmaciones, en agosto de 1796 disponía ya de una primera versión de los cuatro primeros volúmenes de la misma. Fue entonces cuando se dirigió a la Imprenta Real para que le adelantara los fondos necesarios para financiar su impresión, que se ofrecía a reintegrar después con los ingresos de la venta de los volúmenes ${ }^{13}$. Un año después, en agosto de 1797, contando ya con la respuesta afirmativa de esa Imprenta, anunciaba tener finalizado el primer volumen del Curso completo ${ }^{14}$, que remitió a la Matritense tan sólo dos meses después. Así lo hizo también con todos los posteriores. Ello le valió su nombramiento como Socio de Mérito en septiembre de $1799{ }^{15}$ y abrió su etapa de colaboración más estrecha con la institución: durante los tres años posteriores, al tiempo que finalizaba su traducción, ela-

emprendido por alguien como Rozier, que apenas conocía la agricultura española y no había «experimentado» en Francia un proyecto semejante. El ilustrado francés envió su «Bosquejo» también al naturalista español C. Ortega. La documentación pertinente está en el ARSEM, leg. 22-6. Todo ello hace pensar que Rozier y su obra hubieron de resultar bien conocidos por Jovellanos antes de la redacción de su Informe.

12 ARSEM, A/49: Libro de Acuerdos de la Clase de Agricultura de la Real Sociedad Económica de Amigos del País de Madrid que da principio en el mes de Enero de 1788, juntas de $18 / 11$ y $23 / 12$ de 1794.

13 AHN, Consejos, leg. 11282-55. Además del «Prospecto de la traducción» que preparó Álvarez Guerra para difundir su contenido, este expediente reúne, entre otros documentos, el elogioso informe del Juez Conservador de la Imprenta Real sobre la obra de Rozier y sobre su versión española, realizada «con mucha puntualidad y propiedad» y de gran utilidad en el contexto español, al haber añadido el traductor «cientos de artículos de que carecía y son relativos a nuestras producciones, usos y situación local».

14 Existe una edición facsímil reciente de la traducción (Valladolid, 2005).

15 Los envíos de Álvarez Guerra quedan consignados en las juntas de 6/10, 7/11 de 1798, 21/9, 19/10 de 1799, etc., a excepción del relativo al primer volumen. ARSEM, A/110/22 y 23: Libro de Acuerdos de la Real Sociedad (1797-1798 y 1799-1800). Vid., asimismo, leg. 153-8. 
boró para ella numerosos informes de contenido agrario, por petición de su Clase de Agricultura ${ }^{16}$. Así pues, su traducción no se debió a un encargo de la Matritense, si bien ésta constituyó el principal marco institucional de su elaboración y su primer canal de recepción —el propio Álvarez Guerra se presentaba a sus lectores como miembro de la Clase de Agricultura de la Sociedad-. Este mismo carácter semioficial se pone también de relieve en la dedicatoria de la obra a Godoy, debido al «influjo que ha tenido en su publicación» y a «los ojos favorables con que ha mirado la traducción presente».

Otro rasgo distintivo de la traducción fue, como era habitual en obras de esa naturaleza, de carácter enciclopédico y con multiplicidad de disciplinas científicas implicadas en ella, su condición de texto colectivo. Según su propia afirmación, Álvarez Guerra se vio obligado a buscar la ayuda de "químicos, botánicos, físicos, médicos y veterinarios» ${ }^{17}$, si bien no se conoce con exactitud los profesionales que trabajaron bajo su dirección, más allá de su hermano José, cuya colaboración en la traducción fue, con toda probabilidad, muy notable. Este sentido colectivo alcanzaba incluso un cierto rango institucional. Álvarez Guerra parecía estar bien relacionado con las principales instituciones ilustradas oficiales españolas, de las que volcaba en el Curso numerosos informes y artículos (la Escuela Veterinaria de Madrid, diversas Sociedades Económicas, etc.). De alguna manera, su traducción parecía deberse a una estrategia más amplia en la que operaba la coordinación estrecha con el Seminario de Agricultura y Artes. Lo cierto es que éste, en el que esporádicamente escribió Álvarez Guerra —-también lo hizo su padre-, fue otro destacado canal de difusión en España de las ideas agronómicas de Rozier: según Díez (1980, pp. 192-210), en sus diecisiete primeros volúmenes publicó numerosos artículos del Abbé, así como de otros científicos franceses estrechamente vinculados a éste, como Chaptal, Parmentier o Cadet-de-Vaux; y, al mismo tiempo, consintió que diversos artículos y materiales de todo tipo publicados en el Semanario fueran vertidos después en el Curso de Álvarez Guerra. Todo esto era un síntoma también de que su traducción se inscribió en el momento más álgido de la recepción en España de las ideas de Rozier: en 1798, J. Sampil, capellán y mayordomo de Jovellanos, publicó dos libros sobre apicultura y fomento de la plantación cuya fuente principal se ha identificado con el agrónomo francés ${ }^{18}$. Y, en la medida en que esta influencia se

16 El expediente de Álvarez Guerra figura en el ARSEM, leg. 351-14. En cambio, durante 1794-1799 sus asistencias a las juntas habían sido intermitentes y escasas. A partir de 1804 prácticamente se ausentó.

17 AHN, Consejos, leg. 11282-55.

18 Aunque este eclesiástico, que será acusado de afrancesado y liberal tras la reacción absolutista de 1824, no citara a Rozier entre las fuentes de sus escritos, Jovellanos, que tuvo 
mantuvo con posterioridad, su obra puede ser considerada una especie de puente hacia la generación de Arias, Boutelou, Espinosa, etc., según Argemí [1988], la responsable de mantener vivo en España el interés por la agricultura nueva hasta el Trienio liberal.

\section{FISIOCRACIA Y AGRONOMÍA EN LA TRADUCCIÓN ESPAÑOLA DEL COURS DE ROZIER}

Desde la óptica de las ideas económicas, la particularidad más notable de la traducción de Álvarez Guerra era el relativamente extenso «Discurso Preliminar» que lo introducía, obra del propio traductor. Éste reconocía el carácter eminentemente práctico de la obra de Rozier, «más propia para despertar el gusto de los que deseen conocer los medios de fomentar el cultivo de la tierra, que para instruirse a fondo en la Economía Política»; de ahí la trascendencia de ese «Discurso», en el que trataba de sintetizar sus ideas sobre la «agricultura en general» ${ }^{19}$. Aunque Álvarez Guerra citara ocasionalmente algún texto insigne de la Economía Política ilustrada —en concreto, Le commerce et le gouvernement (1776) de Condillac-, su fuente de inspiración era la fisiocracia; en realidad, utilizaba esas páginas para realizar un ilustrativo resumen de sus ideas económicas, tratando de enfatizar su utilidad para la realidad española.

Es indudable que Álvarez Guerra tenía una alta comprensión del análisis económico fisiócrata. Aunque en su «Discurso» no aluda en ningún momento al Tableau Économique ni a la clasificación tripartita fisiócrata en las clases productiva, estéril y de los propietarios, las principales ideas del mismo reposan sobre el modelo de circulación de las rentas ${ }^{20}$, en torno al cual se hallan implicadas las tesis económicas más características de los économistes. Según Álvarez Guerra, la agricultura es el único sector económico capaz de «crear nuevas riquezas». El valor de lo producido por ella depende de los avances: «cuanto mayor son éstos, mayor es el producto del suelo». Precisamente, es la implementación de estos avances, en trabajo o en dinero, la que posibilita que la agricultura produzca no sólo un volumen de frutos superior al que lo haría espontáneamente, sino propiamente por un valor mayor al de los frutos necesarios para alimentar al labrador. Y ello justifica la dedicación a esta

acceso a ambos libros antes de ser publicados — según Clément (1980, p. 208), en el verano de 1797-, los consideró abiertamente derivados de la obra del agrónomo francés. Los dos textos de Sampil (1798a; 1798b), en los que se incidía en la línea de implicar a los párrocos en labores de instrucción y fomento agrarios, fueron dedicados al asturiano, entonces Ministro de Gracia y Justicia, a quien a menudo se ha considerado su posible inspirador.

19 Rozier [1797-1803, vol. I (1797), p. IV].

20 Vid., en particular, Rozier [1797-1803, vol. I (1797), pp. XI-XIII]. 
labor productiva: si el labrador sólo obtuviera el importe de los gastos realizados en el cultivo de su terreno, no existirían incentivos para dedicarse a la misma. El excedente o produit net obtenido en las labores agrícolas incorpora, por norma general, la amortización de los avances, la parte destinada al pago del impuesto directo y el beneficio del propietario del capital ${ }^{21}$, y su realización presupone el caso de una agricultura plenamente comercializada ${ }^{22}$.

Junto a todo ello, el sector agrícola es el principal regulador de la población. Las leyes que condicionan su crecimiento son naturales: «el hombre por naturaleza sigue el impulso de la naturaleza que lo mueve a multiplicar su especie y no se niega a la dulzura del matrimonio»; por ello, las medidas gubernamentales para favorecer artificialmente la población son ineficientes. Tan sólo es necesario definir, con «principios justos, sencillos e invariables», la estructura de la propiedad, cultivar adecuadamente las tierras y liberalizar los intercambios comerciales entre labradores y artesanos, pues los propios mecanismos naturales corregirán, a través de la miseria que seguiría a una situación de escasez, la sobrepoblación; así, la población se ajustará automáticamente a los medios de subsistencia: «la población que puede y debe contener un país será sólo la necesaria para consumir estas subsistencias».

Mientras tanto, los artesanos, es decir, aquellos trabajadores que no se emplean inmediatamente en el cultivo de la tierra, «no producen nada nuevo», sólo dan una forma distinta, «más acomodada a nuestro uso», a la materia prima producida por el sector agrícola. El valor de lo producido por ellos reúne únicamente el valor de la materia prima y el salario del trabajador, de manera que los artesanos venderán al propietario sus obras «por lo que hubiesen sacado de la tierra si se hubieran aplicado a cultivarla para ellos». Por ello, el sector industrial no es "productivo», si bien cumple funciones económicas imprescindibles: absorbe los exce-

${ }^{21}$ Es realmente destacable la percepción por parte de Álvarez Guerra del concepto del beneficio - textualmente, «el premio del capital de la tierra, de su cuidado y del dinero empleado en los avances»-, en cuyo descubrimiento los fisiócratas fueron pioneros, tal y como explicó Meek (1975, pp. 94-120). Precisamente, el extremeño identifica con el nombre de «capitalista» a quien lo busca. En condiciones de competencia, la tasa esperada de las operaciones agrícolas es mayor y más estable que la de las manufactureras, dado que un bien raíz es «una propiedad más constante que la que se emplea en el comercio y en las artes».

${ }^{22}$ En la breve historia con la que introduce su «Discurso», Álvarez Guerra muestra un cierto desprecio por la agricultura de los pueblos antiguos y enfatiza que el verdadero progreso de la agricultura se inició en Gran Bretaña durante el siglo XVII, precisamente cuando aquélla, y no sólo las manufacturas, comenzó a ser considerada un objeto de comercio. La Guerra de Sucesión establecería el punto de inicio de la internacionalización de este interés por las cuestiones agrícolas, que condujo a los soberanos a tratar de «reparar» el tiempo perdido y trajo consigo un desarrollo científico e institucional de indiscutible valía, al cual España se habría incorporado durante el reinado de Carlos III. Vid., Rozier [1797-1803, vol. I (1797), pp. V-VIII]. 
dentes generados por la agricultura —si no lo hiciera «no tendrían ningún valor»-, transforma las materias primas creando una «nueva representación de la riqueza» y, por último, impide que la economía nacional se abastezca del exterior de manufacturas, frenando el incremento del empleo y la población foráneas a costa de las domésticas. En este esquema, el dinero también es «estéril» ${ }^{23}$ : sólo es un signo que posibilita los intercambios comerciales, pero carente de capacidad de aumentar las producciones de la tierra o la industria; de ahí que la idea que lo identifica con la riqueza sea falsa, así como perniciosas aquellas políticas «mercantilistas» favorables a su acumulación a costa de la creación de «riquezas verdaderas».

La productividad del sector agrícola y la esterilidad del manufacturero establecen el marco del modelo comercial más adecuado: «ninguna nación puede hacer el comercio de las artes sin hacer antes florecer la agricultura». Un patrón sustentado en el intercambio de manufacturas nacionales por subsistencias - frutos o materias primas- sería inestable, al estar expuesto "al capricho o a la industria del extranjero». Al mismo tiempo, los pueblos comerciantes están condenados a una subsistencia precaria debido a que sus habitantes, al no estar enraizados en el suelo que habitan, «no tienen amor a la patria y se transportan a la nación que los enriquece» ${ }^{24}$. En suma: «una nación sin cultivo es un conjunto de hombres asalariados por las naciones labradoras» ${ }^{25}$. Así pues, el proceso de circulación de las rentas pivota sobre el prioritario sector agrícola: dado que el artesano se cobra de la agricultura el consumo por el valor de los salarios de su trabajo, el sector agrícola, además de suministrarle las materias primas, es el único que «paga todos sus trabajos». Además, en la medida en que la autoridad pública configure el marco óptimo para el cultivo adecuado de la tierra, el labrador tendrá oportunidad de incrementar sus avances, las tierras producirán más, los sobrantes agrícolas estimularán la creación de artesanos, los bienes manufacturados excederán a las necesidades del labrador y esto propiciará un crecimiento del comercio activo y de bienes de lujo. De ahí que todas las clases sociales dependan, en última instancia, de la clase agrícola, la única que da el «ser a nuevas riquezas» y abre la posibilidad a una economía nacional realmente autónoma.

La ordenación de las políticas económicas más apropiadas para el fomento de la agricultura es también, indiscutiblemente, de raíz fisiócrata. Al margen de ciertas políticas activas a las que se aludirá, el eje de la actuación del gobierno debe dirigirse a favorecer el principio del libre

\footnotetext{
${ }^{23}$ Vid., en particular, Rozier [1797-1803, vol. I (1797), pp. XIV-XV].

24 Rozier [1797-1803, vol. I (1797), p. XVI].

25 Rozier [1797-1803, vol. I (1797), p. XIX].
} 
interés. Para ello, la base institucional del sistema económico debe sustentarse en los derechos individuales del orden natural: «la libertad, la propiedad y la comodidad son los únicos fundamentos de una buena agricultura» ${ }^{26}$. Particularmente relevante resulta establecer con claridad la estructura de la propiedad, tanto la personal y la mobiliaria como, en particular, la de bienes raíces, al ser crucial para la creación de las riquezas. De estos principios se deriva un conjunto de políticas prácticas plenamente enraizadas en el liberalismo fisiócrata. En primer lugar, la desamortización plena y sin condiciones de la propiedad de las tierras, «para que el hombre laborioso pueda adquirirlas con facilidad y el holgazán hacerlas pasar a otras manos en que sean más útiles». A continuación, el respeto escrupuloso a un individualismo agrario que permita al "propietario disponer de su bien», lo cual implica el rechazo de la legislación que, de manera directa o indirecta, determine el modo, el precio y el tiempo de los arriendos, y atente a la libertad en el modo de cultivo o en el establecimiento de los precios agrícolas. Las tasas o las posturas no son "preservativos de la escasez», sino «más funestos a la agricultura que las tormentas y los huracanes»; además, no cumplen ninguno de los objetivos para los que fueron diseñadas: desincentivan al cultivador, no modulan los ciclos de abundancia y escasez, estimulan el fraude de los poderosos e impiden la consecución de precios agrícolas adecuados.

En la misma línea se sitúan las quejas de Álvarez Guerra contra la legislación restrictiva del libre comercio del grano. Frente a lo que han sostenido «algunos partidarios de esta prohibición», que no tienen «la más leve idea de Economía Política», ese régimen que, por otra parte, ya operaba, con relativa laxitud y beneficios indiscutibles, en otros artículos de primera necesidad, como la carne, el aceite o el vino, ayuda a evitar los monopolios y otras formas de concentración de la oferta, pone coto a las operaciones especulativas, atrae comerciantes y caudales al comercio del grano y permite el comportamiento de los agentes económicos de acuerdo con su libre interés, con beneficios que se amplían a toda la colectividad. Asimismo, puede por sí mismo garantizar el abastecimiento del mercado, de ahí que Álvarez Guerra se manifieste contrario a los pósitos públicos y defienda un sistema de almacenamiento privado y fiado «al interés del comerciante». La ampliación de la competencia se presenta, así, como el único medio para despertar el interés del propietario, incentivar su actividad productiva, garantizar la comercialización de los sobrantes y, en particular, limar los beneficios extraordinarios provocados precisamente por la falta de concurrencia:

${ }^{26}$ Rozier [1797-1803, vol. I (1797), p. XLIX]. 
«Acaso no podrá evitarse el que este comercio sea demasiado lucrativo para los primeros que se dediquen a él; pero el atractivo de la ganancia llamará $[\mathrm{a}]$ nuevos comerciantes, hasta que su número sea excesivo; entonces retrogradarán y pararán en el punto medio, esto es, habrá empleados en granos los fondos necesarios para que el consumidor no tema una escasez grande y deje al comerciante una ganancia moderada, y para que el labrador reciba un precio proporcionado no a la abundancia de aquel año, sino al precio que los compradores lo pagarán al comerciante en los siguientes» ${ }^{27}$.

Esos mismos principios de libertad de comercio deben aplicarse al comercio exterior. Buen ejemplo de sus ventajas es Inglaterra, país que debe «los progresos de su agricultura a la libertad y premios pagados por la exportación». En cambio, la limitación a la exportación basada en el sistema de precios, vigente entonces en la legislación española, es perniciosa e inútil, debido a que dificulta las extracciones sin impedir que el comerciante acuda siempre «a hacer sus acopios a los países donde lo encuentra [el grano] más barato». Mientras, la apertura de las fronteras garantiza la importación del grano en los años de escasez y su exportación en los de abundancia sin provocar desabastecimientos, incluso en un país como España, donde las provincias fértiles se encuentran en los mercados interiores. En suma, «fomenten las leyes la labor o, mejor aún, despierten la esperanza del interés del propietario, permitan el comercio interior y la extracción de los sobrantes y ésta será la verdadera tasa, que sostendrá siempre los géneros en un precio medio, tan útil a la agricultura como al consumidor». Esta última idea de establecer un «precio medio» que permita hacer compatible el desarrollo agrícola con el industrial parece distanciar a Álvarez Guerra de la política fisiócrata de bon prix y su origen hubo de encontrarse, con toda probabilidad, de la obra de Condillac (1776, lib. I, cap. XX).

Todos estos conceptos y políticas económicas tienen también incidencia en la estructura del sector público. De acuerdo con los presupuestos fisiócratas, Álvarez Guerra entiende que el gasto público debe ser constreñido. Sus partidas principales deben ir destinadas, por un lado, a establecer el marco constitucional de la economía - seguridad interior, defensa exterior y sistema de justicia- y, por otro, de acuerdo con expresiones e ideas muy cercanas a Jovellanos, a la remoción de los estorbos que «se opongan a la prosperidad y fomento del cultivo» ${ }^{28}$. Es

\footnotetext{
27 Rozier [1797-1803, vol. I (1797), pp. XXV-XXVI].

28 Rozier [1797-1803, vol. I (1797), p. XXIII]. Deberes del Soberano, en cualquier caso, notablemente más reducidos que los atribuidos por Jovellanos, estudiados con detalle por Fuentes Quintana (2000).
} 
decir, aunque la función principal del Soberano sea la de «dejar al labrador el cuidado de fomentar el ramo de cultivo que mejor le parezca, limitándose a protegerlo e inspirarle confianza», existen determinadas situaciones concretas en que debe intervenir de manera activa sobre la realidad económica. Éste es el caso de la construcción de caminos, canales u otras obras públicas en que la agricultura necesite «para prosperar de avances que o superan los esfuerzos de un particular o redundan en beneficio del común». En tal circunstancia el Soberano puede financiar directamente la infraestructura o bien permitir que lo hagan los particulares que se benefician de ella -el caso, principalmente, de los canales de riego-, en cuyo caso tal financiación privada debería materializarse a través del incremento del impuesto sobre el producto neto o cargando una tasa sobre el consumo individual, pero eludiendo siempre el establecimiento de impuestos sobre el comercio dado que elevarían artificialmente el precio de los bienes y restringirían su circulación. En cualquier caso, una vez fijados estos criterios, Álvarez Guerra admite las directrices planteadas por Jovellanos (1795, pp. 324-327) para fijar el orden de prioridad con que estas obras públicas debe ser emprendidas.

También se muestra muy cercano a sus tesis respecto a la conveniencia de que el gobierno se implique en la instrucción del labrador, también en línea con la gran importancia que la fisiocracia otorgaba a las labores educativas. Dicha instrucción debería tener como finalidad enseñarle a encontrar su propio interés, pues, en un marco jurídico estable, allá «donde el labrador estuviese seguro de que el trabajo que ha empleado en su tierra será para él, no descansará hasta encontrar el cultivo más perfecto». No obstante, Álvarez Guerra arroja una visión moderadamente crítica de la manera en que se venía desarrollando en España el proceso de difusión de los conocimientos agrícolas: las cátedras de agricultura no producen los frutos esperados, al estar localizadas preferentemente en contextos urbanos; tampoco las Sociedades Económicas están cumpliendo con sus labores de experimentación agrícola, debido a la escasez de socios y a la falta de financiación; por último, las revistas, cartillas rurales y otras obras destinadas a guiar un cambio en las rutinas de los labradores exceden a su comprensión. Por este motivo, una línea de actuación complementaria debería ser la fundación de escuelas de agricultura destinadas a su formación. Con este fin, Álvarez Guerra recupera el perfil eminentemente docente de Rozier, incrustando en su «Discurso» un amplio y detallado extracto de su proyecto de fundación en Francia de una Escuela Nacional de Agricultura ${ }^{29}$.

${ }^{29}$ Rozier [1797-1803, vol. I (1797), p. XXXII-XL]. El francés fue el primer director de la Escuela de Agricultura (1786) de su ciudad natal de Lyon, así como autor de un detallado proyecto —el extractado por Álvarez Guerra, en línea con el remitido en 1778 a la Matri- 
En cuanto a la financiación del sector público, la suerte del Soberano está también estrechamente ligada a la de la clase agrícola, pues tal financiación ha de provenir del "producto neto de la tierra», una vez descontados de él los avances. Partiendo de este planteamiento, Álvarez Guerra desarrolla una defensa sin fisuras del impôt unique fisiócrata ${ }^{30}$ : al ser la tierra la única fuente de las nuevas riquezas, es lógico que el sistema tributario repose exclusivamente sobre ella. Los impuestos se presentan como una parte del producto neto que el propietario cede al conjunto social a cambio de que el Soberano configure un marco constitucional que garantice la propiedad de la tierra, la posesión de los frutos del trabajo y la seguridad personal.

Con el fin de mostrar las ventajas de un tributo directo sobre el producto neto de la tierra, Álvarez Guerra realiza una exposición valorativa del sistema de impuestos vigente en España: las contribuciones sobre el consumo y las manufacturas generan efectos notablemente perniciosos: elevan el precio de las manufacturas y, por tanto, recaen en última instancia sobre el propietario de la tierra; generan incertidumbres en los agentes sociales, al desconocerse con exactitud qué porción de producto neto equivaldrá al pago del impuesto - por este mismo motivo, el Soberano ignorará también los ingresos públicos esperados-; son especialmente injustos, al cargar buena parte de la carga impositiva sobre las familias de mayor población; y, por último, son muy costosos en cuanto a su gestión, dado que exigen el mantenimiento de un elevado número de recaudadores que, en vez de ocuparse en actividades productivas, viven a «expensas del tributo que recaudan», alteran la tranquilidad de las personas y dificultan la circulación de los frutos y las mercancías. Por su parte, el impuesto directo sobre el producto neto de la tierra - de naturaleza, por tanto, distinta al diezmo, como explica bien Álvarez Guerra- presenta las ventajas exactamente contrarias: no aparta brazos de las actividades productivas; al ser más visible, garantiza la seguridad privada, no daña la circulación de los bienes y ofrece mayor certeza sobre las potencialidades de su recaudación, logrando, de esta manera, incentivar al propietario y que su interés esté estrechamente unido al del Soberano; por último, exige menores gastos en su recaudación, lográndose así eludir la molesta «opresión» de los recaudadores. Álvarez Guerra no sólo trata de mostrar que la habitual oposición de los propietarios a este tipo de impuesto es debida a la «falta de luces» — en realidad, «con menos contribuirían cuanto menores fuesen los gastos de

tense- para la creación en Chambord, en el centro de Francia, de una Escuela Nacional de Agricultura, que presentó para su aprobación en 1790 en una de las primeras Asambleas Nacionales posteriores a la Revolución.

30 Rozier [1797-1803, vol. I (1797), p. XVII-XXI]. 
recaudación»-, sino que además ofrece pautas muy concretas sobre la manera en que este impuesto podría recaudarse en España por medio de encabezamientos municipales ${ }^{31}$, todo lo cual constituye una pormenorizada defensa de aplicación a la realidad española de las ideas tributarias de la escuela de Quesnay.

Si quedara alguna duda acerca de la adscripción fisiócrata del «Discurso» de Álvarez Guerra, éste finaliza con una extensa reflexión acerca de la «agricultura de los chinos» ${ }^{32}$, un tópico especialmente querido entre los économistes ${ }^{33}$. El objetivo de estas páginas, de una notable significación en el contexto de la cultura económica de la Ilustración española, es persuadir a través del ejemplo de esa nación asiática del punto de perfección a que «el tiempo y unas sabias leyes» pueden llevar a la agricultura. De hecho, las páginas recogen un encendido elogio de ese laborioso y populoso país, en particular con relación a su agricultura, que Álvarez Guerra considera notablemente más desarrollada que la europea. Ello se debe tanto al alto nivel de ocupación del suelo, pues sus habitantes «no desperdician un palmo de tierra», como a un conjunto de usos agrarios que «sorprendería al más hábil agrónomo moderno», entre otros, la labor profunda, el uso intensivo de abonos, la selección de las semillas adecuadas para cada terreno, los numerosos canales que contribuyen a fertilizar los campos o la renuncia al barbecho; mientras tanto, la particular dedicación al cultivo del grano y el arroz, en vez de al prado o a los artículos de lujo, justifica su admirada populosidad. Los elogios del liberal extremeño se amplían a la organización socioeconómica de China. El culto público hacia el trabajo, la condena social de la ociosidad o la inexistencia de desigualdades estamentales en el origen han representado factores especialmente favorables al desarrollo agrícola. También lo ha sido la consideración de la agricultura como la principal de las actividades productivas que, desde una tradición ancestral, han mantenido sus autoridades políticas y magistrados, implicándose personalmente en la configuración de la conciencia pública de que se trata de una actividad honorífica, premiando a los labradores distinguidos o garantizando un marco legal basado en los principios de «la libertad, la propiedad y la comodidad», en una baja tributación y en la prohibición de servidumbres y laudemios sobre la propiedad de la tierra. La conclusión que se extrae de todo ello remite, en última instancia, a las ventajas de un sistema social basado en el despotismo legal: China debe

\footnotetext{
31 Rozier [1797-1803, vol. I (1797), p. XXI-XXIII].

32 Rozier [1797-1803, vol. I (1797), p. XLI-LI].

33 Por otra parte, tópico con fuerte presencia en el movimiento agronómico francés y con precedentes en autores tan influyentes como Cantillon, Montesquieu o Melon, tal y como explican, por ejemplo, Weulersse (1910, vol. II, pp. 136-137, 656-657), Bourde (1967, vol. I, pp. 440-444) o Luftalla (1981, pp. 90-95).
} 
la prosperidad de su agricultura a «costumbres sencillas», la existencia de pocas leyes y la derivación de las mismas, de la mano de la autoridad política, de la «naturaleza y la razón». De esta manera, esta especie de despotismo éclairé de la agricultura se presenta como un ejemplo de realización del despotismo legal especialmente apropiado para las realidades española o europea en su conjunto, pues, erróneamente, «hoy la política de Europa sigue un plan diferente: las ciudades están ricas y brillantes, y los pueblos llenos de miseria y suciedad» ${ }^{34}$.

Dejando a un lado el «Discurso Preliminar» y atendiendo ahora al resto de la traducción de Álvarez Guerra, ésta aporta novedades de menor interés que aquél. La cuestión más destacable de la misma radica en el expreso esfuerzo del traductor para adaptar el contenido de las voces originales al contexto español, incluso, en algunos casos, dejándose arrastrar por una indisimulada actitud nacionalista que le lleva a sostener que «en algunos ramos hemos adelantado más que los extranjeros». Para ello, hubo de «acomodar a nuestra práctica» las ideas originales; ampliarlas, matizarlas e, incluso, rectificarlas; «inventar voces nuevas, pues no había equivalentes en castellano»; o, por último, añadir «artículos que explican voces desconocidas en la agricultura francesa». Todo ello se refleja en una traducción en la que la pluma del traductor se halla visiblemente presente.

Las principales contribuciones de Álvarez Guerra, bajo la forma de anotaciones a los artículos originales o de la incorporación de otros de nuevo cuño, son de dos tipos. Un primer grupo, en general, de escaso peso relativo, está relacionado con la economía política agraria. Resulta muy significativo que Álvarez Guerra no recurra en tales añadidos a las ideas fisiócratas. Se trata, más bien, de la defensa de un conjunto de reformas de indudable carácter liberal, y en este sentido en relativa sintonía con las de la escuela francesa, pero, en su espíritu, más próxima al reformismo agrario ilustrado español. En ellas se defiende el libre comercio de los abastos, la libertad de precios, el cercamiento de las heredades, la propiedad individual, el rechazo de los baldíos y la comunidad de pastos, la intensificación de las experiencias agrícolas o la conveniencia de disponer de estudios geográficos y estadísticos sobre la agricultura española ${ }^{35}$. En su defensa Álvarez Guerra recurre ocasionalmente a autores del prestigio de Jovellanos, Cavanilles o Bowles, así como a los textos de viajes de otros insignes ilustrados extranjeros. Ahora bien, en segundo lugar, los principales añadidos del traductor español se concretan en el plano de los usos y las técnicas agrarias o de

\footnotetext{
${ }^{34}$ Rozier [1797-1803, vol. I (1797), p. LI].

35 Algunas de las principales voces con este tipo de contenido eran «abastos», «abierto», «agricultura», «comunidad de pastos» o "geografía física».
} 
los cultivos, así como de los frutos, las plantas o los animales domésticos, lo cual le lleva a incorporar numerosas noticias referidas a la diversa realidad agraria regional de España - y, en algunos casos, también de sus colonias- en todas las disciplinas científicas que abarca el diccionario, más en particular, sobre veterinaria y medicina rural. Aun de forma no sistemática, el Curso se transforma en un canal de difusión de diversas experiencias agrícolas e invenciones técnicas realizadas en España durante las últimas décadas, y ello explica que las siempre presentes fuentes agronómicas francesas (además de Rozier, Daubeton, Parmentier, Duhamel de Monceau, la Encyclopédie Méthodique, etc.) se completen con otras muy representativas de la agronomía ilustrada española (las Memorias de la Matritense, los Extractos de la Sociedad Bascongada, las traducciones de C. Ortega, los artículos del Semanario de Agricultura y Artes, etc.).

\section{UNA ALTERNATIVA FISIÓCRATA AL INFORME DE LEY AGRARIA DE JOVELLANOS}

En una valoración global de la traducción de Álvarez Guerra, su aportación más original radica en el «Discurso» que la introduce. El sustrato fisiócrata del mismo está fuera de toda duda y esto implica a todas las principales vertientes del pensamiento de la escuela francesa, tanto su análisis y política económicos -Tableau Économique y Maximes d'une Royaume Agricole-, como sus concepciones filosóficomorales —Derecho Natural-y políticas - Despotismo legal o de la China- ${ }^{36}$. En el plano estrictamente económico, aún sin mencionar el Tableau Économique, Álvarez Guerra emplea el aparato conceptual propio de los économistes — avances, produit net, etc.—, defiende abiertamente sus tesis económicas más características - la productividad exclusiva de la agricultura, la relación población-subsistencias, etc.-, y sus políticas económicas -impôt unique, individualismo agrario, desamortización de la tierra, libre comercio interior y exterior de granos, etc.-, a excepción de la grande culture y, quizás, el bon prix. Y lo mismo puede afirmarse de los principios políticos —el Despotismo legal—y del orden natural fisiócrata - la propiedad, la seguridad y la libertad-. De esta manera, este ilustrativo «Discurso», que ha pasado totalmente desapercibido en España, tenía la particularidad de orientar hacia la economía fisiócrata la traducción de una obra como la de Rozier, significa-

\footnotetext{
${ }^{36}$ Acerca de esta concepción de la fisiocracia, vid. Faccarello-Steiner (1990, pp. 36 y ss.) y Steiner (1998, pp. 117-125). Otros estudios particularmente útiles sobre la escuela francesa son los de Schumpeter (1954, pp. 223-249), Meek (1962), Hutchison (1988, pp. 273-297) y Steiner (1992, pp. 225-253).
} 
tivamente alejada de la misma. Dado el carácter genérico de la exposición de Álvarez Guerra y debido a que éste no cite sus fuentes, resulta difícil conocer con exactitud cuáles fueron éstas; sin embargo, es claro que en su elaboración utilizó intensivamente los volúmenes sobre Économie Politique y Diplomatique de la Encyclopédie Méthodique ${ }^{37}$. De acuerdo con nuestras propias investigaciones, es muy probable que el origen intelectual de esta pieza fisiócrata se remonte a la figura del profesor salmantino Ramón de Salas, con quien Álvarez Guerra mantuvo un estrecho contacto durante su etapa de estudios universitarios y pudo dar sus primeros pasos en el aprendizaje de la Economía Política ${ }^{38}$.

Por otra parte, el ámbito institucional en el que esa traducción fue realizada — la Sociedad Matritense- y las fechas de la misma -17971803- sugieren que hubo de tratarse de una propuesta alternativa al Informe de Jovellanos. Más allá de diversas expresiones retóricas elogiosas al mismo en el «Discurso» de Álvarez Guerra, en cuanto a contenidos sustantivos, esa obra sólo es mencionada en una ocasión y en relación con la cuestión, normalmente la de menor controversia de la misma, referida a la conveniencia de que el gobierno se responsabilizara de superar los «estorbos de la naturaleza» a través de un ordenado programa de obras públicas. Es indudable que ambos textos poseen un contenido agrarista y liberal compartido, a pesar de lo cual las discrepancias entre ambos son también muy evidentes: se extienden tanto a la propuesta de Álvarez Guerra de organizar el royaume agricole en torno a los principios de libertad, propiedad y seguridad, como a las consecuencias de ello en el ámbito de las reformas económicas. Cuestiones como la desamortización de la tierra, la productividad única de la agricultura, el libre comercio exterior de granos, el rechazo de los pósitos públicos o la tributación directa a través del impôt unique establecen diferencias evidentes entre las posiciones de Álvarez Guerra y Jovellanos.

Estas apreciaciones nos introducen de lleno en una valoración del proceso de circulación de las ideas económicas en la España de finales

\footnotetext{
37 Así parece indicarlo la gran similitud entre las informaciones de Álvarez Guerra y extensas voces del Diccionario, tales como «Agricole»o «Chine», ambas debidas al fisiócrata Grivel, quien volcó en esos y otros numerosos artículos textos previos de Quesnay, Baudeau, Dupont de Nemours o Turgot. También la teoría del impuesto territorial expuesta por el extremeño parece proceder del amplio resumen que sobre ella realizó Grivel de las ideas de Le Trosne. Vid. Panckoucke (1784-1788, vol. I, pp. 57-72 y 543-568). No obstante, se debe recordar que en esos volúmenes no se adoptó una doctrina económica exclusiva — también había numerosas ideas de Necker o Smith—. Vid. Weulersse (1984, pp. 23-24) y Perrot (1992, pp. 127 y ss.).

38 Buena prueba de ello es que Álvarez Guerra fue uno de los testigos que salió en defensa de Salas en el duro juicio al cual la Inquisición le sometió a comienzos de los años noventa. Sobre la adscripción filofisiocrática de los contenidos enseñados por Salas en Salamanca, vid. una primera interpretación en Astigarraga-Usoz (2007).
} 
del siglo XVIII. En los últimos años se viene insistiendo en la conveniencia de desligar el contenido del Informe, tanto de la propia economía fisiócrata, tal y como hicieron en su momento Lluch y Argemí (1985), cuanto de una interpretación que veía la obra como el resultado del «encuentro» de su autor con la Wealth of Nations de Smith ${ }^{39}$. Los detallados estudios recientes de Llombart (2000, pp. 101-110) acerca de las fuentes, «visibles» e «invisibles», del Informe, siempre sin negar la influencia del escocés, vienen a mostrar la mayor cercanía de Jovellanos con otros autores - así, se recupera la trascendencia, por un lado, de tratados como el del francés Condillac y, por otro, de la tradición económica española de Campomanes y los economistas de su generación-, y, por tanto, no sólo la indudable pluralidad de las fuentes empleadas en su elaboración, cuanto su naturaleza de obra de culminación, más que de ruptura, respecto a la tradición económica española cultivada durante el Siglo de las Luces, y aun con anterioridad. Por otra parte, el reformismo pragmático y posibilista de Jovellanos encajaba mal en el liberalismo doctrinario y estricto del laissez faire-laissez passer de los économistes, si bien conviene recordar, una vez más, con Groenewegen (2002, pp. 211-221), que la fisiocracia fue tan solo uno de los puntos de partida del liberalismo francés - y europeo- del siglo XVIII. De hecho, su distanciamiento de aquélla fue una opción perfectamente calibrada por Jovellanos. Una prueba inequívoca de que éste conoció bien sus ideas se encuentra en el hecho de que fuera el autor de la censura del primer volumen de Économie politique et diplomatique de la Encyclopédie Métodique de Panckoucke, de indudable raigambre fisiócrata, en respuesta a una petición del Consejo de Castilla ${ }^{40}$. Pero, por este mismo motivo, la significación del «Discurso» de Álvarez Guerra, con toda probabilidad inspirado en esa fuente, es más notable aún y establece un medido punto de distancia con el Informe de Jovellanos, en línea con los autores que lo recibieron como un programa económico demasiado contenido, más aún después de los resultados tibios que había cosechado el programa ilustrado de comercio libre del grano, vigente entre 1765 y $1789^{41}$.

39 La expresión corresponde a Varela (1988, p. 115). En sintonía con esta interpretación se encuentran también, entre otros, Polt (1978), González (1988), G. Anes (1995) y R. Anes (2000).

40 Según Anes (1996b, pp. 87-97), Jovellanos advertía en su censura de junio de 1785 que el volumen estaba escrito «con aquella especie de libertad de espíritu con que los políticos suelen tratar materias de su facultad». Aunque no encontrara en él cosa alguna que aconsejara «detener su publicación», recomendaba que se rectificase la voz «auto de fe».

41 El debate acerca de los resultados de ese programa sigue abierto. Comprende desde la tesis que sostiene que la liberalización comercial no tuvo efectos en el crecimiento económico y el funcionamiento del mercado de granos, o si los tuvo fueron parciales y debidos 
Su ejemplo más cercano eran, sin duda, las Cartas de Cabarrús. Se ha subrayado, en numerosas ocasiones, que su contenido era más radical que el Informe, el texto que inicialmente le había servido de inspiración. Y ello debido, por un lado, a la manera en que en él se vinculan las reformas económicas con las políticas, y, por otro, a su impronta racionalista, individualista y utilitarista. Como explicó Maravall (1990, p. 19), en esta segunda faceta es especialmente perceptible la influencia de la fisiocracia, si bien, con unos componentes distintos a los empleados por Álvarez Guerra. Tal influencia era muy evidente en la sintonía de Cabarrús con las ideas del orden natural y, en concreto, en su defensa de los «derechos sacrosantos» de libertad, propiedad y seguridad, y de unas leyes «claras, precisas, fijas e independientes de toda autoridad parcial», preferentemente «indirectas» y de sentido «negativo», que, salvo escasísimas excepciones, debían reducirse a «no estorbar» y a «dejar hacer». En buena medida, todo ello explica su análisis más radical que el de Jovellanos en relación con los obstáculos de «opinión» y de «legislación». Ahora bien, en el plano más estrictamente económico, Cabarrús no llegaba tan lejos como Álvarez Guerra en la defensa de un programa fiel al liberalismo fisiócrata. Son bien conocidas sus combativas tesis contra «el sistema impío, absurdo, antisocial de nobleza hereditaria y mayorazgo» (Cabarrús, c. 1795, pp. 136-137), pero en el vertebral terreno de la manera de remover los obstáculos de la «legislación», planteaba prevenciones al libre comercio exterior de granos, y sus ideas fiscales, aunque favorables a la imposición directa, no alcanzaban el extremo del impôt unique fisiócrata. Por otra parte, el hecho de que sus Cartas permanecieran inéditas hasta 1808, viene a ensalzar aún más la adscripción fisiócrata del «Discurso» de Álvarez Guerra e, incluso, su posible intención combativa si pensamos en que fue concebido cuando el Informe se hallaba sometido a un expediente de la Inquisición en el que era calificado de «antieclesiástico» y «antinobiliario». En suma, nos hallamos ante un distinguido miembro de la corriente más radical de la Ilustración tardía española, que de la mano del propio Cabarrús, Foronda, Arroyal, etc., fue tomando forma en el último tramo del siglo XVIII. Y, por último, todo ello vuelve a poner de relieve, en línea con

también a la liberalización del comercio internacional, hasta las que matizan esas posiciones desde visiones moderadamente positivas. Vid., por ejemplo, por este orden, Llopis (2004a, pp. 97-98), Artola (1978, pp. 136v y ss.), Robledo (1993, pp. 15-40), García Sanz (1989, pp. 637638; 1996, pp. 171-172), Castro (1987, pp. 175-177; 1996, pp. 386-387) y Llombart (1992, p. 188). En fechas recientes, Sebastián $(2004$, p. 157) ha insistido en que los ilustrados españoles no supieron aprovechar «todas las oportunidades presentes en su propio marco de restricciones técnicas y medioambientales», al tiempo que Llopis (2004b, pp. 43-46) ha vuelto a reclamar atención sobre el negativo efecto de la herencia del Antiguo Régimen en el desarrollo agrario del siglo XIX español. 
las recientes sugerencias planteadas por Astigarraga (2005b), la necesidad de una reconsideración más matizada de la conocida tesis acerca de la escasa circulación y uso entre los ilustrados españoles - o, en general, ibéricos- de las ideas económicas fisiócratas ${ }^{42}$. Es indudable que los ilustrados españoles tuvieron un buen conocimiento de éstas y, más en particular, de las que fundamentaban la opción favorable al libre comercio de granos, a través de las traducciones de autores fisiócratas originales (Mirabeau, Quesnay, etc.), post-fisiócratas (Condillac y Turgot), divulgadores (Schmid d'Avenstein) o parcialmente fisiócratas, si bien defensores de esa misma opción liberal (Filangieri). De hecho, las primeras tesis favorables al libre comercio de granos que se defendieron en la Ilustración española a partir de la década de los años ochenta, siempre minoritarias, tuvieron como inspiración el modelo fisiócrata incluyendo en esta rúbrica el muy influyente en España texto de Condillac, cuya sintonía con los discípulos de Quesnay respecto a la cuestión del comercio de granos es indiscutible-, tal y como lo ponen de manifiesto casos ya conocidos como los de Villava, Foronda, Salas o Belgrano, y se confirma con el propio «Discurso» de Álvarez Guerra ${ }^{43}$.

Como se ha mencionado, la traducción de Rozier no fue la única contribución de contenido agrario de Álvarez Guerra; todo lo contrario, éste mantuvo vivo durante gran parte de su obra un encendido interés por esas cuestiones, de tal manera que, dada la amplitud cronológica de la misma - su primer texto data de 1798 y el último de 1845-, puede considerarse una especie de puente entre el reformismo ilustrado y el liberalismo españoles; obra puente, en cualquier caso, que hubo de adaptarse a momentos de ruptura notables - en la visión retrospectiva de Álvarez Guerra [1842-1845, vol. I (1842), p. 29], el auténtico tourning point respecto a los lentos "progresos de la civilización y de las luces» vino representado por la Guerra de la Independencia-, y que poseyó dos períodos particularmente intensos en cuanto a su producción intelectual.

El primero tuvo lugar en el marco de los debates económicos de las Cortes de Cádiz. En 1813 Álvarez Guerra publicó una breve memoria destinada a reforzar las tesis de los partidarios de la desamortización de

${ }^{42}$ Vid., principalmente, Lluch-Argemí (1985) y, con criterios diferenciados, Llombart (1995); sobre el caso de Portugal, Almodóvar-Cardoso (1998, pp. 43-51). Un último balance de la difusión internacional de la fisiocracia se encuentra en Delmas-Demals-Steiner (1995, pp. 7-29) y en Argemí-Cardoso-Lluch (1995, pp. 473-480). Conviene recordar que el «Discurso" de Álvarez Guerra se inscribe en el momento en que, según Faccarello-Steiner (1990, p. 39), en Francia y Gran Bretaña se asistía a la «liquidación teórica efectiva de la escuela de Quesnay».

43 Vid., principalmente, Astigarraga (2005a), Barrenechea (1984), Lluch (1984) y Astigarraga-Usoz (2007). 
la tierra, con un cierto sentido de agitación política. De hecho, poco después las Cortes someterían a debate la reforma de la Hacienda Pública y en ese mismo año Álvarez Guerra sería nombrado Ministro de la Gobernación, con amplias competencias sobre el sector agrícola. En síntesis, su propuesta consistía en solventar la incalculable Deuda pública española por medio de un proyecto radical de desamortización de bienes raíces eclesiásticos y comunales municipales, que conllevaba una exigente reforma del sector eclesiástico y la Hacienda pública. Ahora bien, a pesar de que ello conectaba indiscutiblemente con las tesis desamortizadoras expuestas en su «Discurso» a la traducción de Rozier, los fundamentos de sus ideas no eran ya fisiócratas, ni en el plano teórico ni en el normativo, principalmente debido a que la actividad agrícola no era considerada ya como la única "productiva» ${ }^{44}$.

Algo similar puede afirmarse de la etapa que cierra sus contribuciones de contenido agrícola a la causa liberal española. En este caso, éstas se inscriben en el seno de la Sociedad Matritense, durante el período en el que Álvarez Guerra fue su Director (1835-1842). De hecho, él fue uno de los principales impulsores de la realización de un Código rural - como Presidente de la comisión que con ese fin operó en la Sección de Agricultura de la Sociedad-, que vino a representar la rehabilitación del viejo ideario ilustrado de elaboración de una Ley Agraria española ${ }^{45}$. Para afrontar esta cuestión, Álvarez Guerra elaboró dos textos: el Proyecto de una Ley Agraria o Código rural (1841) y una segunda edición del Curso (1842-1845) de Rozier ${ }^{46}$. Ahora bien, en ninguno de ellos se aprecia influencia alguna de la fisiocracia. Álvarez Guerra, aun considerando la agricultura como el principal sector económico, se reafirmó en que no era la única fuente de la riqueza y, en consecuencia, mostró su rechazo a que pudiera disfrutar de un trato preferencial por parte del gobierno; incluso, afirmaba abiertamente que el sector agrícola había perdido ya «su importancia primitiva y absoluta, por efecto natural de los progresos de la población y la civilización», y, en claro rechazo a las ideas fisiócratas, consideraba perjudiciales «todos los sistemas exclusivos de cultivo y todas las teorías seductoras, fruto de la

${ }^{4}$ Vid. Álvarez Guerra (1813). Su memoria, uno de los primeros alegatos desamortizadores de la historia de España, fue muy exitosa; contó con cinco ediciones, incluida una en Méjico, entre 1813 y 1820.

45 El expediente se inició en 1834 y permaneció vivo bajo la iniciativa de la Matritense durante al menos una década. Su objetivo era muy similar al ilustrado: «formar para toda España un cuerpo metódico de disposiciones legales más convenientes al fomento de la industria agrícola», a través de la elaboración de un Código rural "arreglado a la situación y costumbres de nuestro país y a los adelantos del Siglo», que permitiera después emprender la «reforma de nuestra legislación agrícola». Vid. ARSEM, leg. 370-4, y Robledo (1993, pp. 54-57)

46 Vid. Álvarez Guerra (1841) y Rozier (1842-1845). 
imaginación inexperta de algunos agrónomos» ${ }^{47}$. En cualquier caso, las convicciones liberales de Álvarez Guerra se mantuvieron igual de firmes. En la primera obra mencionada, «una colección metódica y ordenada de leyes que se refieren a la agricultura y sus agentes», insistía en la idea de que las leyes agrarias debían limitase a «proteger la libertad individual cuando esté contenida dentro de los límites de la justicia» y, como norma general, limitaba las actuaciones económicas del sector público al fomento de las obras públicas y la instrucción y al viejo ideario ilustrado de remoción de los «estorbos políticos, morales y físicos» a la libre iniciativa individual ${ }^{48}$. Ahora bien, en la práctica reconocía diversas «excepciones» o «restricciones» al principio de «libertad absoluta», entre ellas el control de la exportación del grano utilizando el sistema de precios o la utilidad de determinadas empresas públicas. Sobre estas mismas ideas insistirá en el extenso "Prólogo» a la nueva edición del Curso de Rozier ${ }^{49}$ que, en coherencia con nuestra interpretación, vio la luz sin incluir el extenso «Discurso Preliminar» de contenido fisiócrata que había abierto la primera edición del mismo. En suma, Álvarez Guerra, aunque siempre fiel al liberalismo, renunció muy pronto a las bases fisiócratas de su primera obra de juventud, perfilando un programa de reformas más moderado y pragmático, en suma, con abiertas concesiones al «realismo político», al que pudo verse obligado después de su paso por diferentes responsabilidades políticas del más alto nivel, y que, en algún sentido, le aproximaba más al espíritu que había inspirado el Informe de Jovellanos que al embrión fisiócrata presente en su ideario de juventud ${ }^{50}$.

\section{CONCLUSIONES}

En uno de los numerosos apuntes que dejó para la posterioridad acerca de su ideario económico, Jovellanos escribía respecto al liberalismo

47 Álvarez Guerra [1842-1845, vol. I (1845), p. 25].

48 Álvarez Guerra (1841, pp. 7-10).

${ }^{49}$ Rozier [1842-1845, vol. I (1842), pp. 5-29]. Este Prólogo está configurado básicamente por la traducción de voces procedentes del Cours original, principalmente de la voz «agricultura» [vid. Rozier (1780-1800), vol. I (1780), pp. 252-288], y de ideas extraídas del Proyecto de Ley Agraria o Código rural.

${ }^{50}$ Algo diferente sucedió respecto a sus ideas agronómicas, cuyo éxito se ha de relacionar con el que tuvieron en España las de Rozier durante la larga fase de la agricultura moderna preindustrial, y aun con posterioridad. Ya hemos indicado que el Seminario de Agricultura (1797-1808) incluyó numerosos artículos extraídos del Cours. Además, de acuerdo con Antón (1865, p. 109), uno de los diccionarios de economía rural más importante del siglo XIX, el de Collantes-Alfaro, publicado en 1852-1855, todavía contendrá numerosas voces extraídas del mismo. Una prueba aún más indiscutible de ese éxito se encuentra en la mencionada segunda versión del Curso realizada por Álvarez Guerra. 
doctrinario: «iBellas reflexiones para la retórica!» ${ }^{51}$. Como buen conocedor del pensamiento económico de la Ilustración europea, esta afirmación, no exenta de notable ironía, no era arbitraria y respondía muy bien a la equilibrada posición que su autor había mantenido respecto a ese tipo de liberalismo: salvo algunas contadas y breves memorias elaboradas durante la primera mitad de los años ochenta, Jovellanos guardó siempre una medida distancia respecto del mismo. Su Informe de Ley Agraria, lejos de suponer cualquier acercamiento al ideario del laissez faire-laissez passer, sintonizaba con un liberalismo moderado y gradual y con un reformismo de soluciones templadas y posibilistas que hacían de ese texto un digno punto de culminación de los planteamientos económicos, de carácter analítico y normativo, sostenidos por Olavide, Campomanes y tantos otros ilustrados del reinado de Carlos III. No obstante, con su comentario, Jovellanos quizás estuviera infravalorando la batalla intelectual que otros miembros de su generación habían abierto durante las dos décadas finales del siglo XVIII, en algunos casos, incluso, inducidos por la publicación de su Informe, siguiendo precisamente ese liberalismo doctrinario que él trataba con fina ironía. El caso de J. Álvarez Guerra en su primera etapa como publicista vuelve a poner de relieve la existencia de estrategias de desarrollo económico alternativas a la presentada en el Informe de Jovellanos. Ejemplos muy cercanos al mismo fueron dos autores protagonistas de la Ilustración radical y tardía española, Foronda y Cabarrús. Es evidente que ambos tuvieron un conocimiento profundo de la fisiocracia y que estuvieron parcialmente influidos por ella; sin embargo, ninguno mantuvo la adscripción fiel —casi canónica- al ideario de los économistes, en sus vertientes tanto económica, como política y filosófico-moral, como ese liberal extremeño. Ello convierte el «Discurso» que ha sido objeto principal de este trabajo en uno de los textos más característicamente fisiócratas de toda la Ilustración española. Esta cuestión posee importantes repercusiones interpretativas respecto a, al menos, dos cuestiones distintas: una reconsideración más positiva de la presencia de las ideas de la escuela de Quesnay en nuestras Luces y la aceptación de que la opción liberal y librecambista doctrinaria fue una parte consustancial al programa económico de la Ilustración española, si bien siempre minoritaria.

\section{FUENTES}

Archivo Histórico Nacional (AHN, Madrid): Estado: leg. 3182-151 y 2932-23; Consejos, leg. 11282-55.

${ }^{51}$ Citado por Llombart (2000, p. 98). 
Archivo de la Real Sociedad Económica Matritense de Amigos del País (ARSEM, Madrid): libros A/49, A/110/22 y A/110/23; leg. 22-6, 153-8, 351-14 y 370-4.

ARchivo Histórico del SENAdo (AHS, Madrid): His-0024-06.

\section{BIBLIOGRAFÍA}

Almodovar, A., y Cardoso, J. L. (1998): A History of Portuguese Economic Thought, London y New York: Routledge.

Álvarez Guerra, J. (1813): Modo de extinguir la deuda pública, eximiendo a la Nación de toda clase de contribuciones por espacio de diez años; y ocurriendo al mismo tiempo a los gastos de la guerra, y demás urgencias del Estado, Cádiz: Imprenta Tormentaria.

- (1841): Proyecto de una Ley Agraria o Código rural publicado de acuerdo de la Sociedad Económica Matritense, Madrid: Miguel de Burgos.

ANES, G. (1995): La ley agraria, Madrid: Alianza.

- (1996a): «Del Expediente de Ley Agraria al Informe de Jovellanos», en A. García SAnZ y J. SAnz Fernández (eds.), Reformas y políticas agrarias en la historia de España, Madrid: Ministerio de Agricultura, Pesca y Alimentación, pp. 69-103.

- (1996b): «La Inquisición en la Encyclopédie: una censura inédita de Jovellanos», en J. Álvarez Barrientos y J. Checa Beltrán (coords), El siglo que llaman ilustrado. Homenaje a Francisco Aguilar Piñal, Madrid: CSIC, pp. 87-97.

ANES, R. (2000): «De las ideas de Jovellanos sobre la economía y la actividad económica», en E. Fuentes Quintana (dir.), Economía y economistas españoles. Vol. III: La Ilustración, Barcelona: Círculo de Lectores-Galaxia Gutenberg, pp. 315-329.

ANTÓN RAMírez, B. (1865): Diccionario de bibliografía agronómica y de toda clase de escritos relacionados con la agricultura, seguido de un indice de autores y traductores con algunos apuntes bibliográficos, Madrid: Rivadeneira.

ARGEMí, Ll. (1985): «Agronomía y revolución agraria en España (1750-1820)», en E. Lluch y Ll. ARgemí, Agronomía y fisiocracia en España (1750-1820), Valencia: Institución Alfonso el Magnánimo, pp. 1-43.

- (1992): «Nueva agronomía y agrarismo en la España ilustrada», en Estructuras Agrarias y reformismo ilustrado en la España del siglo XVIII, Madrid: Ministerio de Agricultura, Pesca y Alimentación, pp. 553-563.

- (comp.) (1988): Agricultura e Ilustración, Madrid: Ministerio de Agricultura, Pesca y Alimentación.

Argemí, Ll.; Cardoso, J. L., y Lluch, E. (1995): «La diffusion internationale de la physiocratie: quelques problèmes ouverts», en B. Delmas, T. Demals y Ph. STEINER (eds.), La diffusion internationale de la physiocratie (XVIIIe-XIXe), Grenoble: Presses Universitaires, pp. 473-480.

Artola, M. (1978): Antiguo Régimen y revolución liberal, Barcelona: Editorial Ariel. Astigarraga, J. (2005a): «La prima versione spagnola della Scienza della Legislazione di Gaetano Filangieri», en A. Trampus (ed.), Diritti e costituzione. L'opera di Gaetano Filangieri e la sua fortuna europea, Bologna: Il Mulino, 2005, pp. 61-84.

- (2005b): «La fisiocracia en España: los Principes de la législation universelle (1776) de G. L. Schmid d'Avenstein». Historia Agraria, 37, pp. 545-571. 
Astigarraga, J., y ZabalzA, J. (2006): La Economía en los diccionarios y las enciclopedias del siglo XVIII en España. Documento de Trabajo de la AEHE, DT-0607 (http//:altea.daea.ua.es/aehe/).

Astigarraga, J., y Usoz, J. (2007): «Political Economy and Republicanism in late Eighteenth Century Spain: R. de Salas, Apuntaciones to A. Genovesi's Lezioni di commercio», en P. F. Asso y L. Fiorito (eds.), Economics and Institutions. Contributions from the History of Economic Thought, Milan: Franco Agneli, pp. 343-367.

BARRENECHEA, J. M. (1984): Valentín de Foronda, reformador y economista ilustrado, Vitoria: Diputación Foral de Álava.

Bourde, A. J. (1967): Agronomie et agronomes en France au XVIIIe siècle, Paris: SEVPEN, 3 vols.

CABARRUS, F. (c. 1795): Cartas sobre los obstáculos que la naturaleza, la opinión y las leyes oponen a la felicidad pública, Madrid: Fundación Banco Exterior, 1990.

CAstro, C. de (1987): El pan de Madrid. El abasto en las ciudades españoles del Antiguo Régimen, Madrid: Alianza.

- (1996): Campomanes, Estado y reformismo ilustrado, Madrid: Alianza.

CLÉMENT, J. P. (1986): Las lecturas de Jovellanos (ensayo de reconstitución de su biblioteca), Oviedo: Instituto de Estudios Asturianos.

CONDILlac, É. B. de (1776): Le commerce et le gouvernement, considérés relativement l'un à l'autre, ed. de E. Daire, Mélanges d'Économie Politique, Paris: Guillaumin, 1847.

Delmas, B.; Demals, T., y Steiner, Ph. (1995): «Presentation: les physiocrates, la science de l'économie politique et l'Europe», en B. Delmas, T. Demals y Ph. STEINER (eds.), La diffusion internationale de la physiocratie (XVIIIe-XIXe), Grenoble: Presses Universitaires, pp. 7-29.

DÉrozier, A. (1978): Quintana y el nacimiento del liberalismo en España, Madrid: Turner.

Díez Rodríguez, F. (1980): Prensa agraria en la España de la Ilustración: el Semanario de Agricultura y Artes dirigido a los párrocos (1797-1808), Madrid: Ministerio de Agricultura.

Domergue, L. (1969): «La Real Sociedad Matritense de Amigos del País y la prensa periódica», Moneda y Crédito, 109, pp. 25-58.

- (1971): Jovellanos à la Société Économique des Amis du Pays de Madrid (17781795), Toulouse: Université de Toulouse-Le Mirail.

Enciso, L. M. (1958): Prensa económica del XVIII: el Correo Mercantil de España y sus Indias, Valladolid: Universidad de Valladolid.

Faccarello, G., y Steiner, Ph. (1990): «Prelude: une génération perdue?», en G. Faccarello y $\mathrm{Ph}$. Steine (eds.), La pensée économique pendant la Révolution française, Grenoble: Presses Universitaires, pp. 9-56.

Fuentes Quintana, E. (2000): «Una aproximación al pensamiento económico de Jovellanos a través de las funciones del Estado», en E. FuENTES Quintana (dir.), Economía y economistas españoles. Vol. III: La Ilustración, Barcelona: Círculo de Lectores-Galaxia Gutenberg, pp. 331-420.

GARCía DE LA BARRENA, I. (1992): Una perspectiva en la vida intelectual española del primer tercio del siglo XIX: José Álvarez Guerra y su ambiente, Barcelona: Universitat de Barcelona (tesis doctoral).

GARCía SANZ, A. (1974): «Agronomía y experiencias agronómicas en España durante la segunda mitad del siglo XVIII», Moneda y Crédito, 131, pp. 29-54. 
- (1989): «La política agraria ilustrada y sus realizaciones», en Estructuras Agrarias y reformismo ilustrado en la España del siglo XVIII, Madrid: Ministerio de Agricultura, Pesca y Alimentación, pp. 629-638.

- (1996): «La reforma agraria de la Ilustración: proyectos y resultados. El precedente del arbitrismo agrarista castellano», en A. GARCía SANZ y J. SANZ FERNÁNDEZ (eds.), Reformas y políticas agrarias en la historia de España, Madrid: Ministerio de Agricultura, Pesca y Alimentación, pp. 161-200.

Gil Novales, A. (1991): Diccionario biográfico del Trienio liberal, Madrid: El Museo Universal.

GoNZÁLEZ, M. J. (1988): «Campomanes y Jovellanos ante el marco institucional de la economía de mercado», Información Comercial Española, 656, pp. 103-113.

Groenewegen, P. (2002): Eighteenth-century Economics, London y New York: Routledge.

Hutchison, T. W. (1988): Before Adam Smith. The Emergence of Political Economy, 1662-1776, Oxford: Basil Blackwell.

JAIME Lorén, J. M. a de, y JAIME Gómez, J. de (2003): «Aspectos apícolas en los escritos y traducciones del ilustrado extremeño Juan Álvarez Guerra», Revista de estudios extremeños, 59-2, pp. 871-898.

Jovellanos, G. M. de (1795): Informe de la Sociedad Económica de Madrid al Real y Supremo Consejo de Castilla en el Expediente de Ley Agraria, edición de V. Llombart, Madrid: Real Academia de Ciencias Morales y Políticas, 2000, pp. $185-342$.

KAPLAN, S. L. (1976): Bread, Politics and Political Economy in the Reign of Louis XV, The Hague.

Luftalla, M. (1981): Aux origines de la pensée économique. Prodomes, épigones et périparadigmatiques, Paris: Económica.

Llombart, V. (1992): Campomanes, economista y político de Carlos III, Madrid: Alianza.

- (1995): «Market for ideas and reception of Physiocracy in Spain: some analytical and historical suggestions", European Journal of the History of Economic Thought, 1, pp. 29-51.

- (2000): «Jovellanos, economista de la Ilustración tardía», Estudio Preliminar a G. M. de Jovellanos, Escritos económicos, Madrid: Real Academia de Ciencias Morales y Políticas, pp. 1-177.

Llopis, E. (2004a): «Campomanes, la Pragmática de 1765 y los mercados de cereales antes y después de la reforma», en F. Comín y P. MARTín Aceña (eds.), Campomanes y su obra económica, Madrid: Instituto de Estudios Fiscales, pp. 73-104.

- (2004b): «España, la "Revolución de los modernistas" y el legado del Antiguo Régimen», en E. Llopis (ed.), El legado económico del Antiguo Régimen en España, Barcelona: Crítica, pp. 11-76.

Lluch, E. (1984): Acaecimientos de Manuel Belgrano fisiócrata, y su traducción de las máximas del gobierno económico de un reino agricultor de Quesnay, Madrid: Ediciones de Cultura Hispánica e Instituto de Cooperación Iberoamericana.

Lluch, E., y Argemí, Ll. (1985): Agronomía y fisiocracia en España (1750-1820), Valencia: Institución Alfonso el Magnánimo.

Maravall, J. A. (1973): "Cabarrús y las ideas de reforma política y social en el siglo XVIII», Prólogo a F. CABARrús, Cartas sobre los obstáculos que la naturaleza, 
la opinión y las leyes oponen a la felicidad pública, Madrid: Fundación Banco Exterior, 1990, pp. 7-34.

Meek, R. L. (1962): The Economics of Physiocracy, ed. española La fisiocracia, Barcelona: Ariel, 1975.

PANcKoucke, Ch. J. (1784-1788): Encyclopédie Méthodique, ou par ordre de matières ; par une Société de gens de lettres, de savants et d'artistes. Économie Politique et Diplomatique, Paris: Chez Panckoucke.

Pérez González, F. T. (1995): Juan Álvarez Guerra. Ciencia y conciencia agronómica, Mérida: Editora regional extremeña.

- (2000): El pensamiento de José Álvarez Guerra, Madrid: Universidad Autónoma de Madrid (tesis doctoral).

Perrot, J. C. (1992): Une histoire intellectuelle de l'Économie Politique, Paris: EHESS.

PolT, J. H. E. (1978): «El pensamiento económico de Jovellanos y sus fuentes inglesas», Información Comercial Española, DXII, pp. 23-56.

RoBlEDO, R. (1993): Economistas y reformadores españoles: la cuestión agraria (1760-1935), Madrid: Ministerio de Agricultura, Pesca y Alimentación.

RozIER, A. (1781-1800): Cours complet d'agriculture, théorique, pratique, économique, et de medecine rurale et véterinaire, suivi d'une méthode pour étudier l'agriculture par principes, ou Dictionnaire universel d'agriculture, Paris, 10 vols.

- (1797-1803): Curso completo, o Diccionario universal de agricultura teórica, práctica, económica, y de medicina rural y veterinaria. Escrito en francés por una Sociedad de agrónomos, y ordenado por el Abate Rozier, Madrid: Imprenta Real, 16 vol. (traductor: Juan ÁlvVAREZ GUERRA).

- (1842-1845): Nuevo Diccionario de agricultura, teórica-práctica y económica, y de medicina doméstica y veterinaria, del Abate Rozier, Madrid: I. Boix, 13 vols. (traductor: Juan ÁlvAREZ GuERRA).

SAmPIL, J. A. (1798a): Nuevo plan de colmenas, o Tratado histórico-natural, físico-económico de las abejas, Madrid: Benito Cano.

- (1798b): El jardinero instruido, o tratado físico de la vegetación, cultivo y poda de los árboles frutales, Madrid: Benito Cano.

Schumpeter, J. A. (1954): History of Economic Analysis, New York: Oxford University Press.

SEBASTIÁN Amarilla, J. A. (2004): «La agricultura española y el legado del Antiguo Régimen (1780-1855)», en E. Llopis (ed.), El legado económico del Antiguo Régimen en España, Barcelona: Crítica, pp. 147-186.

SteInER, Ph. (1992): «L'Économie Politique du Royaume Agricole», en A. BÉraud y G. FACARELlo (eds.), Nouvelle historique de la pensée économique, Paris: Éditions La Découverte.

- (1998): La «science nouvelle» de l'Économie Politique, Paris: Presses Universitaires de France.

VARELA, J. (1988): Jovellanos, Madrid: Alianza.

Villalba, J. de (s. a.): Diccionario de higiene y economía rural y veterinaria (manuscrito), BNE.

Weulersse, G. (1910): Le mouvement physiocratique en France. De 1756 à 1770, reed. Genève: Slatkine Reprints, 2003, 2 vols.

- (1984): La physiocratie à l'aube de la Révolution, 1781-1782, Paris: EHESS. 